\title{
The relations between anger, coping with anger, and aggression, and the BIS/BAS system
}

\author{
Dirk J.M. Smits *, Peter Kuppens \\ Department of Psychology, K.U. Leuven, Tiensestraat 102, B-3000 Leuven, Belgium
}

Received 3 August 2004; received in revised form 28 January 2005; accepted 6 February 2005

Available online 12 May 2005

\begin{abstract}
In two studies, the relations between the experience and expression of anger and the Behavioral Inhibition System/Behavioral Approach System were investigated with self-report data. In a first study, our results replicated previous findings that trait anger relates positively to both BIS and BAS, and generalized these findings to a measure of trait anger based on contextual anger responses. In a second study, the relations between anger coping-styles, anger expression, and BIS/BAS were examined. It was hypothesized that coping with anger involves low activity of either BIS or BAS, resulting in the anger coping styles of angerout and anger-in, respectively. Measures of anger-out were found to be positively related to a measure of BAS and negatively to a measure of BIS, whereas the opposite pattern of associations was obtained for anger-in. Furthermore, corresponding to an anger-out coping style, both physical and verbal aggression were found to be positively related to BAS, and negatively to BIS.
\end{abstract}

(C) 2005 Elsevier Ltd. All rights reserved.

Keywords: Behavioral inhibition system; Behavioral approach system; Trait anger; Coping with anger; Aggression

\footnotetext{
* Corresponding author. Tel.: +32 16326133.

E-mail address: dirk.smits@psy.kuleuven.ac.be (D.J.M. Smits).
} 


\section{Introduction}

It has been argued that two systems lie at the base of the regulation of emotion and behavior (Depue \& Iacono, 1989; Fowles, 1980; Gray, 1987, 1990): (1) The Behavioral Inhibition System (BIS) deals with aversive motivation and avoidance behavior; its primary purpose is preventing or stopping behavior that is expected to lead to punishment or the cessation/loss of reward. As such, BIS activity has been related to the experience of negative emotions, in particular anxiety (Arnett \& Newman, 2000; Carver \& White, 1994; Gray, 1987, 1990). (2) The Behavioral Approach System (BAS) deals with appetitive motivation and approach behavior. It is activated by conditioned stimuli of reward or opportunities to avoid or stop punishment. It energizes behavior directed at acquiring the rewards or eliminating the punishment (Depue \& Iacono, 1989). As such, BAS has been related to the experience of positive emotions (Carver \& White, 1994; Gable, Reis, \& Elliot, 2000; Gray, 1990).

Recently, however, several authors have argued that BIS and BAS may not be uniquely related to either negative or positive emotions (Carver, 2004; Corr, 2002; Harmon-Jones, 2003; Putman, Hermans, \& van Honk, 2004). In particular, the emotion of anger can be considered to have a negative affective component (relating it to BIS activity) as well as an approach-motivated component (relating it to BAS activity). As such, anger has been hypothesized to result from activity of both BIS and BAS.

With the present research, we aim to examine the relation between different aspects of anger on the one hand and BIS/BAS on the other hand. In a first study, we aim to replicate and further generalize previous findings on the relation between trait anger and BIS/BAS. In a second study, we aim to more closely examine the relations between anger coping-styles and the expression of anger on the one hand, and BIS/BAS on the other hand.

\section{Study 1: Trait anger and BIS/BAS activity}

We hypothesize that anger, amongst other things consists of a component related to negative affect and an approach action-related component, resulting in positive relations between trait anger and both BIS and BAS. With respect to anger and BIS, both have been associated with general negative affect or neuroticism (Berkowitz, 2000; Carver \& White, 1994; Costa \& McCrae, 1992; Watson, 2000). Furthermore, anger is considered an emotion that is accompanied by a negatively valenced hedonic tone (Lazarus, 1991); moreover, in his influential account of anger and aggression, Berkowitz (2000) argued that anger can generate from negative affect. With respect to anger and BAS, the former is accompanied by a clear approach motivation-antagonism (Averill, 1983; Frijda, 1986). Thus, although anger has a negative affective value, also BAS may be hypothesized to play a role in anger (Carver, 2004; Harmon-Jones, 2003). Previous research has indeed revealed that individual differences in BAS are positively associated with individual differences in trait anger (Harmon-Jones, 2003). Furthermore, it has been shown that increased left-prefrontal cortical activity and decreased right prefrontal cortical activity - a correlate of approach motivation or BAS - is associated with state anger (Harmon-Jones \& Allen, 1998), especially when there is something the person can do to resolve the anger-inducing situation (Harmon-Jones, Sigelman, 
Bohlig, \& Harmon-Jones, 2003), and with trait anger (Harmon-Jones, 2003; Harmon-Jones \& Sigelman, 2001).

In previous research that related anger to BIS/BAS activity, trait anger has been assessed with general trait questionnaires or with lists of anger-related adjectives (Harmon-Jones, 2003; Harmon-Jones \& Allen, 1998). However, both types of instruments measure trait anger without any reference to the context in which anger is experienced. Yet, emotional experience is highly context-sensitive as it originates from an interaction between the person's concerns and the demands imposed by the situation (Frijda, 1986; Mischel \& Shoda, 1995). In addition, also BIS and BAS are assumed to respond to specific contextual cues (see higher). Therefore, in a first study we will examine whether the previously found relations between trait anger and BIS/BAS can be replicated when using a measure of trait anger that is based on a contextual anger assessment (via a directed imagination task) in which participants have to rate their anger experience in response to hypothetical situations. The sum over situations will be used as a context-driven measure of trait anger.

As a further replication of previous results, we will examine whether the link between trait anger and BIS can be explained by their common association with general negative affect. In the current study, neuroticism will be used as a measure of negative affect (Markin, Krueger, \& Watson, 2005; Meyer \& Shack, 1989; Watson, Clark, \& Harkness, 1994).

\subsection{Method}

\subsubsection{Subjects}

The participants were 323 first year psychology students (49 males and 274 females, average age $=18.6, \mathrm{sd}=2.7)$. Participation in the study was a partial fulfillment of a requirement to participate in research.

\subsubsection{Materials}

To assess individual differences in BIS and BAS sensitivity, the Dutch translation of Carver and White's (1994) BIS/BAS questionnaire was administered (Smits \& De Boeck, submitted for publication). The questionnaire comprises one BIS scale and three BAS scales. Although the three BAS scales are positively correlated (Heubeck, Wilkinson, \& Cologon, 1998) — as would be expected since they all reflect the same emotional system - combining them into one scale is not warranted given the factorial structure of the questionnaire (Heubeck et al., 1998; Smits \& De Boeck, submitted for publication). The BIS scale measures concern over the possibility of a bad occurrence and sensitivity to such events when they do occur. The BAS Drive scale (BASD) reflects the persistent pursuit of desired goals, the BAS Fun Seeking scale (BASF) reflects a desire for new rewards and to approach a potentially rewarding event, and the BAS Reward Responsiveness scale (BASR) reflects a focus on positive responses to the occurrence or anticipation of reward (Carver \& White, 1994). Note that none of the BAS items refers to an adverse event or negative affect; the opposite is true for the BIS items (Carver, 2004). The responses were collected using a four-point scale $(1=$ strongly agree to $4=$ strongly disagree $)$. In order to obtain scale scores, the respective item scores are summed per scale.

A context-free measure of trait anger (TA) was obtained with the Dutch adaptation (Van Der Ploeg, Defares, \& Spielberger, 1982) of the 10-item Trait anger scale (Spielberger, 1980). The 
measure is called "context-free" because almost all items (except 2) contain no reference to the context in which anger occurs. A sample item is "I am a hotheaded person". The responses were collected using a four-point scale $(1=$ almost never to $4=$ almost always).

A context-driven measure of TA was obtained via a directed imagery task. Each participant received 15 vignettes with situation descriptions. The situations were taken from existing situation-response inventories of Endler and Hunt (1968), who selected situations which are likely to evoke anger or represent what Rosenzweig (1944) considers to be personal frustrating events (for a complete description of the vignettes, see Smits, De Boeck, \& Vansteelandt, 2004). Participants were asked to read every vignette carefully and to imagine oneself as vividly as possible what one would feel when being in such a situation. Subsequently, for every vignette they were asked to rate on a three-point scale the degree to which they would feel angry in that particular situation $(0=$ not angry, $1=$ angry to some extent, and $2=$ angry to a strong extent $)$. An example of such a situation is "Your instructor unfairly accuses you of cheating in an examination". The mean response over situations was used as a context-driven measure of TA.

Finally, neuroticism was assessed with the Neuroticism-scale of the Dutch translation of the NEO-FFI (Costa \& McCrae, 1992; Hoekstra, Ormel, \& de Fruyt, 1996). In total, this scale comprises 12 items. Participants indicated their responses on a scale from 1 (strongly disagree) to 5 (strongly agree).

\subsubsection{Procedure}

The BIS/BAS measures and the TA measures were collected in sessions with at most 30 participants at a time. The neuroticism measure was collected in a separate session. For 277 of the participants, data from all three measures (BIS/BAS, TA, and neuroticism) were available.

\subsection{Results}

The means and the standard deviations for the BIS/BAS scales, the Spielberger TA scale, the context-driven TA measure from the directed imagery task (TA context), and the neuroticismscale are given in Table 1.

The correlation between both measures of TA was reasonably high $(r=.44, p<.01)$. The correlations between the BIS/BAS scales and the two TA measures are given in Table 2. TA seems to

Table 1

Descriptive statistics (Study 1)

\begin{tabular}{llll}
\hline & $N$ & Mean & SD \\
\hline BIS & 323 & 21.46 & 3.69 \\
BASD & 323 & 10.38 & 2.31 \\
BASF & 323 & 11.65 & 1.93 \\
BASR & 323 & 16.74 & 1.95 \\
TA & 323 & 22.32 & 5.74 \\
TA context & 323 & 17.17 & 4.58 \\
Neuroticism & 277 & 34.25 & 8.54 \\
\hline
\end{tabular}


Table 2

Correlations between BIS/BAS and TA (Study 1)

\begin{tabular}{lllll}
\hline & BIS & BASD & BASF & BASR \\
\hline TA & $.23^{* * *}$ & $.12^{* *}$ & .04 & .07 \\
TA context & $.20^{* *}$ & $.23^{* *}$ & .04 & $.16^{* *}$ \\
\hline
\end{tabular}

${ }^{*}$ Significant at the .05 level.

** Significant at the .01 level.

Table 3

Standardized regression weights for hierarchical regressions of BIS, BASD, BASF, BASR and neuroticism on TA (Study 1)

\begin{tabular}{lllrrr}
\hline & BIS & BASD & BASF & BASR & Neuroticism \\
\hline TA & $.26^{* *}$ & $.13^{*}$ & .07 & -.04 & \\
TA & .07 & $.15^{*}$ & .08 & -.04 & $.32^{* *}$ \\
TA context & $.21^{* *}$ & $.24^{* *}$ & -.01 & .05 & $.16^{*}$ \\
TA context & .13 & $.23^{* *}$ & .00 & .06 & .06 \\
\hline
\end{tabular}

${ }^{*}$ Significant at the .05 level.

** Significant at the .01 level.

be primarily correlated with BIS and BASD. Only the context-driven measure of TA was positively correlated with BASR.

TA and BIS were both associated with neuroticism. The correlation of neuroticism with TA equals .33, the correlation with TA context equals .20, and the correlation with BIS equals .55 (all $p<.01)$. To test whether the association between TA and BIS is primarily due to the fact that both are associated with negative emotionality or neuroticism, both measures of TA were first predicted by BIS, BASD, BASF, BASR, and second, in addition to the BIS/BAS scales, neuroticism was added as a predictor (see Table 3). From the first set of regressions, it can be concluded that trait anger is primarily associated with BIS and BASD. ${ }^{1}$ In the second set of regressions, neuroticism and BASD were the only significant predictors, whereas BIS was not significant anymore, suggesting that anger and BIS are related due to the overlap of anger and BIS with neuroticism. Gender $($ male $=0$, female $=1$ ) had no significant effect for any of the two TA measures above the effects of neuroticism and BASD.

\subsection{Discussion}

Both the context-free and the context-driven measure of TA showed the predicted correlations with the BIS/BAS scales: Both measures of TA were positively correlated with BIS and with BASD; TA context was also correlated with BASR. Thus, taking specific contextual factors into account when measuring TA does not seem to alter the relations between TA and BIS/BAS.

\footnotetext{
${ }^{1}$ We also tested the contribution of the statistical interaction between BIS and each BAS subscale in six separate regression analyzes. The results revealed five non-significant interactions. Only for TA context, the BIS $\times$ BASR interaction was significant $(\beta=-1.41, p=.01$, partial $r=-.15)$.
} 
Further, as in prior research, the current findings suggest that BAS and general negative affect independently contribute to anger, and that the correlation between BIS and trait anger is due to an overlap of BIS and anger with negative affect.

A possible reason for the consistent finding that TA is associated with BASD in particular may be found in appraisal theories of emotions: The appraisal of goal-blocking is generally accepted as an important determinant of anger (Averill, 1983; Ellsworth \& Smith, 1988; Kuppens, Van Mechelen, Smits, \& De Boeck, 2003; Smith \& Lazarus, 1993), whereas the BASD scale measures the persistent pursuit of desired goals. It may be that the more a person actively pursues his or her goals (high BASD), the higher is the probability that goal-obstacles are encountered or perceived, resulting in more intense and frequent anger (higher TA).

\section{Study 2: Coping with anger, expression of anger, and BIS/BAS activity}

\subsection{Coping with anger and BIS/BAS activity}

Anger coping is often conceptualized in terms of anger-out and anger-in (Averill, 1983; Spielberger, Johnson, \& Jacobs, 1982). Anger-out refers to the tendency to express one's anger outwardly, usually directed at the target of one's anger. As such, it corresponds to the release of anger's prime action tendency, antagonism. As the latter clearly implies approach-oriented action (Frijda, 1986; Kuppens, Van Mechelen, \& Meulders, 2004), we expect anger-out to be positively related to BAS. BIS, in contrast, is primarily aimed at the inhibition of behavior. As anger-out implies the lack of inhibition of the behavioral tendency accompanying anger (Smits et al., 2004), we expect anger-out, in contrast to TA, to be negatively related to BIS.

Anger-in refers to the tendency to turn one's anger-inwards, implying anger regulation by suppression (Greenglass, 1996; Julkunen, 1996; Schwenkmezger \& Hank, 1996). According to recent research (Smits et al., 2004), to have an anger-in coping style means to inhibit the antagonistic action tendencies or aggressive inclinations that accompany anger, rather then inhibiting the anger. Also, the strongest behavioral inhibition is assumed to occur for high BIS and low BAS activity (Corr, 2002). Therefore, we expect anger-in to be positively related to BIS, but, in contrast to trait anger, negatively to BAS.

\subsection{The expression of anger and BIS/BAS activity}

As mentioned above, the action tendency accompanying anger is antagonism, and the expression of this tendency can result in aggression (Averill, 1983; Berkowitz, 1993). Two broad types of aggression can be distinguished: physical aggression and verbal aggression. Both types refer to an outward expression of anger, which essentially results from an anger-out coping mechanism. Therefore, it is expected that both are positively related to BAS, and negatively to BIS. Previous research indeed demonstrated a positive association between BAS and offensive aggression (Harmon-Jones \& Sigelman, 2001), and between BAS and physical aggression (Harmon-Jones, 2003). Furthermore, a negative association between BIS and physical aggression has been obtained as well (Harmon-Jones, 2003). 


\subsection{Method}

\subsubsection{Subjects}

The participants were 261 first year psychology students (55 males and 206 females, average age $=18.5, \mathrm{sd}=3.1$. Participation in the study was a partial fulfillment of a requirement to participate in research.

\subsubsection{Materials and procedure}

Similar to Study 1, individual differences in BIS and BAS activity were assessed with the Dutch translation of Carver and White's (1994) BIS/BAS questionnaire (Smits \& De Boeck, submitted for publication).

The anger coping-styles are measured with the Anger-out and Anger-in scales of the SelfExpression and Control Scale (SECS, Van Elderen, Maes, Komproe, \& van der Kamp, 1997), an adaptation of the Anger Expression Scale (Spielberger et al., 1982). An example of an Anger-out item is "When angry or furious, I start squabblin", and of an Anger-in item is "When angry or furious, I keep my anger in restraint". The responses were collected using a four-point scale $(1=$ almost never to $4=$ almost always $)$.

The tendencies to display physical and verbal aggression were measured with the corresponding scales from the Dutch adaptation of the Buss-Perry Aggression Questionnaire (BPAQ, Buss \& Perry, 1992; Claes, Vertommen, \& Ponnet, 1999). This questionnaire also comprises a TA scale, called the Anger scale, which was also administered. An example of a physical aggression item is "If somebody hits me, I hit back", an example of a verbal aggression item is "When people annoy me, I may tell them what I think of them", and an example of an Anger item is "I flare up quickly but get over it quickly". The responses were collected using a five-point scale ( $1=$ not applicable to $5=$ highly applicable).

\subsection{Results}

The means and the standard deviations for the BIS/BAS scales, the SECS scales, and the BPAQ scales are given in Table 4. The intercorrelations reported in Table 5 show that the Anger scale from the BPAQ was positively associated with both BIS and BAS, replicating the results obtained in Study 1. When regressing the Anger scale on the BIS/BAS scales, the effects of BIS, BASD and BASF were positive and significant $(p<.01)$, suggesting that this measure is somewhat more BASoriented than the TA measure of Spielberger (1980).

The results in Table 5 further show that Anger-out and the two aggression variables are negatively correlated with BIS, and positively with the BAS scales. Anger-in displays an opposite pattern of correlations: It is positively correlated with BIS and negatively with the BAS scales.

Anger-out and both aggression variables were strongly correlated with the Anger scale (.42 for Anger-out, .54 for Physical Aggression, and .44 for Verbal Aggression, all $p<.01$ ) meaning that there is an overlap between Anger and those variables. In order to assess how these variables relate to BIS/BAS independently from Anger, it is necessary to control for Anger. Therefore, three hierarchical regression analyses were performed with the BIS/BAS scales as predictors and with Anger-out or one of the aggression variables as dependent variable, while controlling for Anger (see Table 6). The result showed that, without controlling for Anger, Anger-out is related to BAS 
Table 4

Descriptive statistics (Study 2)

\begin{tabular}{llll}
\hline & $N$ & Mean & SD \\
\hline BIS & 259 & 21.91 & 3.88 \\
BASD & 259 & 10.30 & 2.48 \\
BASF & 259 & 11.82 & 2.17 \\
BASR & 259 & 16.71 & 2.03 \\
Anger-out & 260 & 23.72 & 6.46 \\
Anger-in & 258 & 24.13 & 6.47 \\
Physical aggression & 259 & 18.55 & 7.31 \\
Verbal aggression & 258 & 15.74 & 3.46 \\
Anger & 259 & 18.28 & 5.14 \\
\hline
\end{tabular}

Table 5

Correlations between BIS/BAS, SECS, and BPAQ (Study 2)

\begin{tabular}{lcccc}
\hline & BIS & BASD & BASF & BASR \\
\hline Anger-out & $-.16^{*}$ & $.29^{* *}$ & $.30^{* *}$ & $.16^{*}$ \\
Anger-in & $.22^{* *}$ & $-.19^{* *}$ & $-.19^{* *}$ & -.09 \\
Physical Aggression & $-.21^{* *}$ & $.29^{* *}$ & $.29^{* *}$ & $.13^{*}$ \\
Verbal Aggression & $-.27^{* *}$ & $.31^{* *}$ & $.35^{* *}$ & $.22^{* *}$ \\
Anger & $.13^{* *}$ & $.23^{* *}$ & $.25^{* *}$ & $.19^{* *}$ \\
\hline
\end{tabular}

${ }^{*}$ Significant at the .05 level.

** Significant at the .01 level.

Table 6

Hierarchical regressions of BIS/BAS on anger-out or on an aggression variable controlling for Anger (Study 2)

\begin{tabular}{llllll}
\hline & BIS & BASD & BASF & BASR & Anger \\
\hline Anger-out & -.12 & $.16^{*}$ & $.19^{* *}$ & .08 & - \\
Anger-out & $-.19^{* *}$ & .09 & .12 & .07 & $.38^{* *}$ \\
Physical Aggression & $-.17^{*}$ & $.16^{*}$ & $.17^{*}$ & .08 & - \\
Physical Aggression & $-.27^{* *}$ & .06 & .07 & .07 & $.53^{* *}$ \\
Verbal Aggression & $-.26^{* *}$ & .12 & $.18^{* *}$ & $.19^{* *}$ & - \\
Verbal Aggression & $-.35^{*}$ & .05 & .09 & $.18^{* *}$ & $.43^{* *}$ \\
\hline
\end{tabular}

${ }^{*}$ Significant at the .05 level.

** Significant at the .01 level.

and Physical aggression and Verbal aggression are related to BIS and BAS. Note here that the regression coefficient of BIS for Anger-out approaches significance $(p=.08)$. After controlling for Anger, almost all associations between the BAS scales and anger-out/aggression variables disappear, whereas the associations with BIS remain. The correlation between Anger-in and Anger was not significant $(r=-.07, p=.24)$. Finally, gender $($ male $=0$, female $=1)$ only had a significant negative effect for Physical Aggression $(\beta=-.19, p<.01)$. 


\subsection{Discussion}

As expected, anger-out, verbal, and physical aggression all showed a similar pattern of correlations with the BIS/BAS scales: All three variables were negatively related to BIS and positively to BAS. In prior research, Smits et al. (2004) found that to have an anger-out coping style means to follow one's tendency to act aggressively and not to inhibit that tendency. This is confirmed by the current results as anger-out is associated with the opposite of inhibition (low BIS and high BAS). Anger-in, in turn, was found to be characterized by an opposite pattern: a positive relation with BIS and a negative with BAS, reflecting inhibitory processes.

The results from the regressions showed that when controlling for Anger, the anger-out coping style and both aggression scales were negatively associated with BIS, whereas almost all associations with BAS disappeared. Interestingly, this suggests that independent from the experienced anger itself that motivates the tendency for aggression, aggressivity is primarily due to low inhibitory activation (BIS) instead of strong approach-motivating activity (BAS). In other words, when two persons are equally prone to experience anger, whether they are also inclined to behave aggressively or not, will depend primarily on their additional (lack of) inhibitory BIS activity, and not on their differences in approach-related BAS activity.

Only for physical aggression were gender differences found: Women had lower values for physical aggression than men. This finding is in line with other research on gender differences in overt aggression (Archer, 2004) and it suggests that the inhibition of aggression is somewhat stronger for women than for men (Smits et al., 2004). In previous research, Crane-Ross, Tisak, and Tisak (1998) and Richardson and Green (1999) found that women more than men consider aggressive behavior to be socially unacceptable and a reason to be concerned about negative self-evaluation and negative effects on others. As physical aggression can be considered a less acceptable or a less common variant of aggression compared with verbal aggression, this may explain why women reported less physical aggression.

\section{Conclusions}

Traditionally, activity of BIS and BAS were thought to be responsible for respectively, negative and positive emotions. Recently, theorists have argued that both systems may play a role in specific positive and negative emotions. The results from Study 1 corroborated this reformulation of the relation between BIS/BAS activity and emotional experiences: It was found that the tendency to experience anger is positively associated with BIS and BAS. Further, the relationship between TA and BIS was found to be mediated by negative affect or neuroticism, in line with findings of Harmon-Jones (2003). The results regarding anger coping and expression demonstrated that anger-out and aggression are characterized by high BAS and low BIS activity, whereas the opposite pattern was found for anger-in (Study 2). Thus, BIS is related to the inhibition of aggressive impulses. The effects of BAS on outward expression, however, were found to be mediated by anger.

The findings of the studies here are subject to two caveats. First, although the individual differences strategy seems a useful strategy to investigate our hypotheses, one should realize that results based on individual differences do not automatically generalize to intra-individual differences. 
Second, the methods used were correlational, and as such subject to limitations of correlational designs (e.g. direction of causality, third variables causing correlations). Further research should extend the present research by manipulating BIS and BAS activity and assessing changes in experienced anger, anger coping, and aggression.

\section{Acknowledgment}

The research is financially supported by grants GOA 2000/2, PDM/04/078, and PDM/04/071 from the K.U. Leuven Research Fund.

\section{References}

Archer, J. (2004). Sex differences in aggression in real-world settings: A meta-analytic review. Review of General Psychology, 8, 291-322.

Arnett, P. A., \& Newman, J. P. (2000). Gray's three-arousal model: An empirical investigation. Personality and Individual Differences, 28, 1171-1189.

Averill, J. R. (1983). Studies on anger and aggression: Implications for theories of emotion. American Psychologist, 38, $1145-1160$.

Berkowitz, L. (1993). On the formation and regulation of anger and aggression. American Psychologist, 45, 494-503.

Berkowitz, L. (2000). Causes and consequences of feelings. Cambridge, UK: Cambridge University Press.

Buss, A. H., \& Perry, M. (1992). The aggression questionnaire. Journal of Personality and Social Psychology, 63, 452-459.

Carver, C. S. (2004). Negative affects deriving from the behavioral approach system. Emotion, 4, 3-22.

Carver, C. S., \& White, T. L. (1994). Behavioral inhibition, behavioral activation, and affective responses to impending reward and punishment: The BIS/BAS scales. Journal of Personality and Social Psychology, 67, 319-333.

Claes, L., Vertommen, H., \& Ponnet, E. (1999). Psychometrische eigenschappen van de 'aggression questionnaire' [Psychometric properties of the 'aggression questionnaire']. Diagnostiekwijzer, 3, 95-107.

Corr, P. J. (2002). J.A. Gray's reinforcement sensitivity theory and frustrative nonreward: A theoretical note on expectancies in reactions to rewarding stimuli. Personality and Individual Differences, 32, 1247-1253.

Costa, P., \& McCrae, R. R. (1992). Revised NEO personality inventory (NEO-PI-R) and the five factor inventory (NEOFFI): Professional manual. Odessa, Florida: Psychological Assessment Resources Inc.

Crane-Ross, D., Tisak, M. S., \& Tisak, J. (1998). Aggression and conventional rule violations among adolescents. Journal of Consulting and Clinical Psychology, 81, 322-331.

Depue, R. A., \& Iacono, W. G. (1989). Neurobehavioral aspects of affective disorders. Annual Review of Psychology, 40, 457-492.

Ellsworth, P. C., \& Smith, C. A. (1988). From appraisal to emotion: Differences among unpleasant feelings. Motivation and Emotion, 12, 271-302.

Endler, N. S., \& Hunt, J. M. (1968). S-R inventories of hostility and comparisons of the proportions of variance from persons, behaviors, and situations for hostility and anxiousness. Journal of Personality and Social Psychology, 9 , 309-315.

Fowles, D. C. (1980). The three arousal model: Implications of Gray's two-factor learning theory for heart rate, electrodermal activity, and psychopathy. Psychophysiology, 17, 87-104.

Frijda, N. H. (1986). The emotions. Cambridge: University Press.

Gable, S. L., Reis, H. T., \& Elliot, A. J. (2000). Behavioral activation and inhibition in everyday life. Journal of Personality and Social Psychology, 78, 1135-1149.

Gray, J. A. (1987). The psychology of fear and stress. Cambridge, England: Cambridge University Press.

Gray, J. A. (1990). Brain systems that mediate both emotion and cognition. Cognition and Emotion, 4, $269-288$.

Greenglass, E. R. (1996). Anger suppression, cynical distrust and hostility: Implications for coronary heart disease. Stress and Emotion: Anger, Anxiety, and Curiosity, 16, 205-225. 
Harmon-Jones, E. (2003). Anger and the behavioral approach system. Personality and Individual Differences, 35, 995-1005.

Harmon-Jones, E., \& Allen, J. J. B. (1998). Anger and frontal brain activity: EEG asymmetry consistent with approach motivation despite negative affect valence. Journal of Personality and Social Psychology, 74, 1310-1316.

Harmon-Jones, E., \& Sigelman, J. (2001). State anger and prefrontal brain activity: Evidence that insult-related relative left-prefrontal activation is associated with experienced anger and aggression. Journal of Personality and Social Psychology, 80, 797-803.

Harmon-Jones, E., Sigelman, J. D., Bohlig, A., \& Harmon-Jones, C. (2003). Anger, coping, and frontal cortical activity: The effect of coping potential on anger-induced left frontal activity. Cognition and Emotion, 17, 1-24.

Heubeck, B. G., Wilkinson, R. B., \& Cologon, J. (1998). A second look at Carver and White's (1994) BIS/BAS scales. Personality and Individual Differences, 25, 785-800.

Hoekstra, H. A., Ormel, J., \& de Fruyt, F. (1996). Handleiding NEO persoonlijkheidsvragenlijsten NEO-PI-R and NEO-FFI [Manual of the NEO personality inventories NEO-PI-R and NEO-FFI]. Lisse, The Netherlands: Swets Test Services.

Julkunen, J. (1996). Suppressing your anger: Good manners, bad health? Stress and Emotion: Anger, Anxiety, and Curiosity, 16, 227-240.

Kuppens, P., Van Mechelen, I., \& Meulders, M. (2004). Every cloud has a silver lining: Interpersonal and individual differences determinants of anger-related behaviors. Personality and Social Psychology Bulletin, 30, 1550-1564.

Kuppens, P., Van Mechelen, I., Smits, D. J. M., \& De Boeck, P. (2003). The appraisal basis of anger: Specificity, necessity and sufficiency of components. Emotion, 3, 254-269.

Lazarus, R. S. (1991). Emotion and adaptation. New York: Oxford University Press.

Markin, K. E., Krueger, R. F., \& Watson, D. (2005). Delineating the structure of normal and abnormal personality: An integrative hierarchical approach. Journal of Personality and Social Psychology, 88, 139-157.

Meyer, G. J., \& Shack, J. R. (1989). Structural convergence of mood and personality: Evidence for old and new directions. Journal of Personality and Social Psychology, 57, 691-706.

Mischel, W., \& Shoda, Y. (1995). A cognitive-affective system theory of personality: Reconceptualizing situations, dispositions, dynamics, and invariance in personality structure. Psychological Review, 122, 246-268.

Putman, P., Hermans, E., \& van Honk, J. (2004). Emotional Stroop performance for masked angry faces: It's BAS, not BIS. Emotion, 4, 305-311.

Richardson, D. R., \& Green, L. (1999). Social sanction and threat explanations of gender effects on direct and indirect aggression. Aggressive Behavior, 25, 425-434.

Rosenzweig, S. (1944). An outline of frustration theory. In J. M. Hunt (Ed.), Personality and the behavior disorder (pp. 379-388). New York, NY: Ronald Press.

Schwenkmezger, P., \& Hank, P. (1996). Anger expression and blood pressure. Stress and Emotion: Anger, Anxiety, and Curiosity, 16, 241-259.

Smith, C. A., \& Lazarus, R. S. (1993). Appraisal components, core relational themes, and the emotions. Cognition and Emotion, 7, 233-269.

Smits, D.J.M., De Boeck, P., (submitted for publication). From BIS/BAS to the big five. European Journal of Personality.

Smits, D. J. M., De Boeck, P., \& Vansteelandt, K. (2004). The inhibition of verbally aggressive behavior. European Journal of Personality, 18, 537-555.

Spielberger, C. D. (1980). Preliminary manual for the state-trait anger scale (STAS). Tampa, Florida: University of South Florida.

Spielberger, C. D., Johnson, E. H., \& Jacobs, G. A. (1982). The anger expression (AX) scale. Tampa, Florida: University of South Florida.

Van Der Ploeg, H. M., Defares, P. B., \& Spielberger, C. D. (1982). Zelf analyse vragenlijst (ZAV) (State-trait anger scale). Lisse, The Netherlands: Swets \& Zeitlinger.

Van Elderen, T., Maes, S., Komproe, I., \& van der Kamp, L. (1997). The development of an anger expression and control scale. British Journal of Health Psychology, 2, 269-281.

Watson, D. (2000). Mood and temperament. New York: Guilford Press.

Watson, D., Clark, L. A., \& Harkness, A. R. (1994). Structures of personality and their relevance to psychopathology. Journal of Abnormal Psychology, 103, 18-31. 